\title{
Modelling of tree-induced effects on pedestrian exposure to road traffic pollution
}

\author{
C. Borrego, J. Valente, J. H. Amorim, V. Rodrigues, \\ P. Cascão \& A. I. Miranda \\ CESAM and Department of Environment and Planning, \\ University of Aveiro, Portugal
}

\begin{abstract}
According to the United Nations Environment Programme (UNEP) information in 2009 , at least 1 billion people are exposed to outdoor air pollution that exceeds the air quality standards of the World Health Organization (WHO). Poor air quality in urban areas, mainly associated with the transportation sector, has been directly linked to almost 0.8 million premature deaths annually, especially in sensitive groups such as children. In this context, the role of trees on improving urban air quality has been discussed. However, there is still a scarce understanding on the ultimate impact of trees over the exposure of pedestrians.

This paper evaluates the exposure of students in their daily walk to/from school, and how it relates with the effect of trees over the local concentrations of road traffic-emitted air pollutants. The study is focused on an area of $0.38 \times 0.22 \mathrm{~km}^{2}$ centred at a high school of the city of Aveiro, in central Portugal, which is located close to a road with significant traffic. A period of one day was chosen, based on data availability. Time evolution of georeferenced location of an individual was tracked with a GPS for different alternative walking routes to the school. Air quality and meteorological data were measured in the school yard. Simulations of carbon monoxide $(\mathrm{CO})$ concentrations in the study domain were performed with the Computational Fluid Dynamics (CFD) model VADIS, with and without considering the influence of trees over the dispersion. Traffic emissions were estimated with the TREM model, using traffic counts (with vehicles categories discretization) data.

Simulated wind speed and CO concentrations were compared with measured values showing a very good agreement (normalized mean square error, NMSE, equals 0.29 and 0.04 , respectively). An exposure model was developed that associates the georeferenced location of the student with the computed air quality
\end{abstract}


levels (at an average breathing height) for that specific grid cell. The model calculates the individual exposure at each time frame and the integrated value for a given period and a given route. Results have shown that, depending on wind flow behaviour, trees can promote or inhibit the ventilation of vehicle's emissions in the street-canyon. Also, knowledge-based routing can promote a lower exposure to air pollutants in typical daily travels. The variability of the estimated exposure values shows the magnitude of the error that can be committed when using a single value of air quality as a surrogate of air pollution exposure.

Keywords: CO exposure, urban pathways, CFD modelling, urban trees.

\section{Introduction}

Air pollution is the environmental factor with the highest impact on health in Europe and is responsible for the largest burden of environment-related diseases [1]. Since the 1990s numerous studies have demonstrated the association between outdoor air pollutants concentration, and the occurrence of health related problems [2-5]. In particular, some authors [6-9] have found associations between exposure to traffic and adverse health effects, such as hypertension, myocardial infarction, stroke, atherosclerosis, heart disease and mortality. Nevertheless, most studies on health effects of traffic exposure mostly rely on associations between hospital records and data from air quality monitoring stations, considered as representative of exposure in a large geographical area. In order to evaluate the real impacts of air pollution on the population health is necessary to undergo a complete assessment of the human exposure to atmospheric pollutants, that includes using direct measurements or modelled data of air pollutants concentrations in every microenvironment that an individual (or population group) occupies, and the time fraction spent in each.

Although traditionally associated with environmental benefits, the presence of trees, or other vegetation, interferes with the dispersion of air pollutants, resulting both in the improvement or decrease in air quality [10].

Even though the effects of plant canopies on atmospheric turbulence have been significantly studied, a scientifically-based knowledge of the overall impact of trees on urban environments is still needed, specifically concerning the outcomes on air quality. It was shown that urban morphology (i.e. the 3D configuration of buildings and streets) significantly affects the dispersion of air pollutants within a street canyon $[11,12]$. Furthermore, the complexity of the wind flow inside the street-canyon is significantly increased by the presence of urban vegetation, which is known to modify the recirculating flow inside the street-canyons and the vortex structures, in terms of number and arrangement, which govern the vertical exchange rates of pollutants. This type of behaviour has been presented by field campaigns [13], wind tunnel experimentation [14] and numerical modelling [15-16]. Nevertheless, the extent of the resulting perturbations on air pollutants dispersion in complex urban geometries is still difficult to simulate, and the extent of the impacts on air quality are still not entirely understood. This paper evaluates the exposure of students in their daily 
walk to a school, and how it relates with the effect of trees over the local concentrations of road traffic-emitted air pollutants.

\section{Modelling system description}

With the purpose of evaluating the air pollution exposure of students in their daily walk to school and the effect of trees over the local concentrations of road traffic-emitted air pollutants, and, consequently, over the students' exposure, a local scale modelling system was used. This system includes two main models, one for estimating air quality and other to estimate the individual exposure.

\subsection{Air quality modelling}

Local scale air quality modelling was carried out using the Computational Fluid Dynamics (CFD) model VADIS, which was developed at the University of Aveiro (UAVR), Portugal [17]. In this model the 3D wind flow is simulated applying a RANS prognostic model with a standard k- $\varepsilon$ turbulence closure. For the dispersion VADIS uses a Lagrangian approach. This model incorporates also the URban VEgetation canopy module, URVE [10], which is intended for the simulation of the effect of vegetation over the wind flow and air pollutants dispersion. The main concept behind URVE involves the extension of the standard mean flow and turbulence equations, through the inclusion of additional source terms when coupled to a CFD model, allowing it to mathematically represent the effect of leaves and branches over the wind field. Consequently, the dispersion of the emitted air pollutants is conditioned by the disturbed wind flow, with effects that depend most of all on the characteristics of the vegetation itself and of the incoming air flow. The loss of wind speed due to pressure and viscous drag forces exerted by the leaves and branches is accounted in the model as a sink term that is added to the momentum conservation equation, which is dependent of the leaf area density (LAD) of each individual tree. Similarly, the turbulent interaction between the airflow and the plant canopy is addressed by including additional source terms in the transport equations of the turbulent kinetic energy and its dissipation. Additional information about URVE can be found in [10].

\subsection{Exposure modelling}

It is important to distinguish the concepts of concentration and exposure. While the first is a physical characteristic of the environment at a given place and time, the latter quantifies the interaction between the polluted atmosphere and the person [24]. MEB [25], the exposure model used in this research, was developed with the objective of providing the estimate of the individual exposure of firefighters, but it can be also used also in other environments (outdoor, indoor, or a combination of both).

In the core of MEB is the calculation of the individual exposure through the following general expression (which is a simplification of the microenvironment 
approach from Hertel et al. [2001], since in this case only one microenvironment exists):

$$
\exp _{i}=C_{i} \times t_{i}
$$

where $\exp _{i}$ is the total exposure for the person $i$ over the specified period of time; $C_{j}$ is the pollutant concentration in a given location, and $t_{i}$ is the time spent by the person $i$ in that specific location. As a result, the exposure value is expressed in concentration $\times$ time $\left(\right.$ e.g. $\left.\mu \mathrm{g} \cdot \mathrm{m}^{-3} \cdot \mathrm{h}\right)$, and thus can be interpreted as the mean pollutant concentration value to which the individual has been exposed during a given period of time (e.g. 1 hour).

The input data for this model is the following:

- the temporal variation of the individual location: this information is provided by the GPS equipment with predefined temporal resolution;

- the temporal variation of the spatial distribution of concentrations at an average inhalation height.

By cross-walking, in each time-step, the georeferenced positioning of the individual with the corresponding concentration, the model tracks the time evolution of the exposure.

The output data produced by MEB are both instant and mean exposure values.

\section{Model application and results}

Air quality simulations were conducted with VADIS for a period of 31 hours [10], according to the averaging period defined for CO by Directive 2008/50/CE. These simulations are from 5 p.m. on May $4^{\text {th }}$ to 12 a.m. on May $5^{\text {th }} 2004$. In order to evaluate the effects induced by the vegetation canopy, simulations were performed with the URVE module activated and deactivated. Road traffic emissions were estimated using the Transport Emission Model for Line Sources (TREM), also developed at the UAVR [17], using detailed data on vehicles counting.

Individual exposure to $\mathrm{CO}$ was calculated with $\mathrm{MEB}$, for seven different pathways, all leading to a secondary school, centered in the air quality simulation domain. Aiming to focus the analysis on a peak period we have selected the morning rush hour of 8-9 a.m. (on May $5^{\text {th }} 2004$ ). Since the classes start at 8 h30 in the morning, the walk of students to the school is covered by the analysis. The seven pathways were defined recurring to GPS tracking. An individual covered the paths carrying a GPS, simulating the journey of seven different students.

Fig. 1 illustrates the chosen pathways within the domain.

\subsection{Air quality}

Due to the limited time and space scales of the analysis CO can be considered as a non-reactive chemical species. Also, the $\mathrm{CO}$ removal by the canopy was neglected, due to its insignificant relevance (approximately $0.0015 \%$ of the CO concentration in ambient air according to [27]). For more details about the modeling procedures and configurations see [10]. 


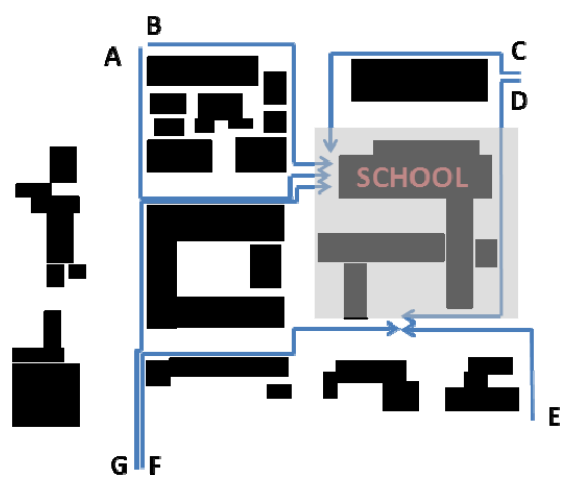

Figure 1: Pathways to school for exposure calculation.

A brief description of the computational domain and input data for the simulation is given in table 1 .

Table 1: General description of the computational domain.

\begin{tabular}{|c|c|}
\hline Location & $\begin{array}{c}\text { Aveiro } \\
\text { study case }\end{array}$ \\
\hline $\begin{array}{l}\mathrm{L} \times \mathrm{W} \\
\left(\mathrm{m}^{2}\right)\end{array}$ & $380 \times 220$ \\
\hline $\begin{array}{l}\mathrm{H} / \mathrm{W} \\
\text { ratio } \\
\end{array}$ & 0.75 \\
\hline $\begin{array}{l}\text { Mesh: type, } \\
\text { resolution }\left(\mathrm{m}^{3}\right) \\
\text { number of cells }\end{array}$ & Regular, 1000, 38400 \\
\hline $\begin{array}{c}\text { Buildings: number } \\
\text { of blocks, height range (m) }\end{array}$ & $40,3-15$ \\
\hline $\begin{array}{l}\text { Trees: number of blocks, } \\
\text { species, height range } \\
(\mathrm{m}), a\left(\mathrm{~m}^{2} \cdot \mathrm{m}^{-3}\right), c_{d}\end{array}$ & $\begin{array}{c}\text { 29, Acer pseudoplatanus } \\
\text { and Quercus robur, } \\
10,1.08,0.2\end{array}$ \\
\hline $\begin{array}{l}\text { Number of roads } \\
\text { and width }(\mathrm{m})\end{array}$ & $12,4-20$ \\
\hline
\end{tabular}

In fig. 2 the temporal variation of the mean hourly values of measured and modeled wind velocity and CO concentrations is presented. The data comparison reveals a good agreement between measured and simulated values over the entire period. Although in some periods there is an overestimation of concentrations when URVE is used, there is a general increase of modeling performance when the vegetation effect is taken into account. This effect is notorious in the case of wind speed.

Modelling performance and accuracy was evaluated applying the model acceptance criteria defined by [28] for air quality models assessment. The 

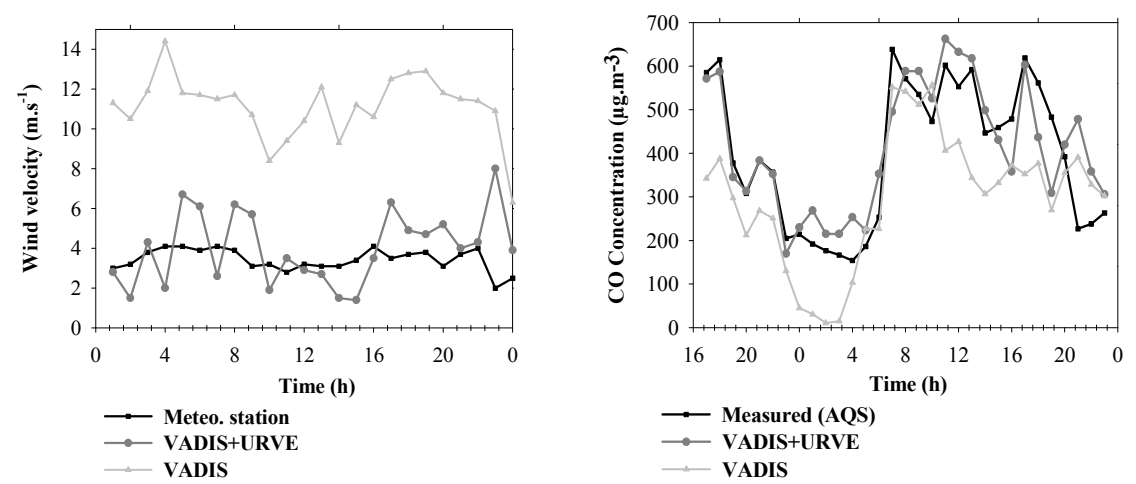

Figure 2: Time evolution of the mean hourly values of wind velocity (left figure) and $\mathrm{CO}$ concentration (right figure) measured in the air quality station (AQS) and simulated for the same location with and without the inclusion of URVE.

statistical analysis indicates a better modelling performance when the vegetative canopy is considered. The normalized mean squared error (NMSE) is reduced from 0.14 to 0.04 . Nevertheless, in both cases, the NMSE for the simulations is significantly lower than the maximum of 1.5 defined as the acceptance criteria. The Pearson correlation coefficient also increases with the URVE module utilization indicating a better correlation between modelled and measured data. Modelling uncertainty was assessed through the data air quality objectives established by the Directive 2008/50/CE. According to the results obtained the maximum deviation of 50\% was surpassed attaining 59.7\%, when URVE is not used. This parameter decreases to $18.9 \%$, with the consideration of the trees canopy, allowing the fulfillment of the requirements established by legislation.

Fig. 3 presents the $\mathrm{CO}$ concentration fields for the air quality simulation for the two considered situations, with and without vegetation.
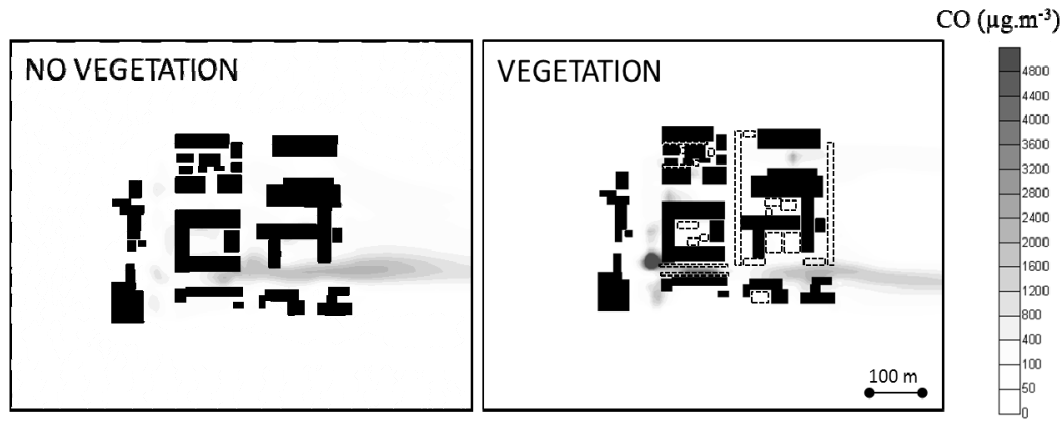

Figure 3: Comparison of $3 \mathrm{~m}$ height horizontal $\mathrm{CO}$ concentration fields with (right figure) and without (left figure) the effect of trees, for the period between 8 and 9 a.m. Unfilled dashed rectangles indicate trees blocks and the circle is the AQS. 
The effect of trees on air quality is spatially dependent, mostly because the heterogeneous positioning of trees induces complex wind flow patterns. Moreover, the orientation of the incoming wind in relation to the positioning of the emissions sources, buildings and trees is a determinant factor. Consequently, while the air quality of specific areas in the study domain benefit from the action of trees over the wind flow, others do not [17]. We have concluded from the analysis of this particular time period (8-9 a.m.) that the trees rows on both side of the avenue exert a "canyoning effect" over the wind flow, inducing the formation of a hot-spot over its central axis (traffic lanes). Therefore, there is a decrease of the $\mathrm{CO}$ concentrations on the sidewalks even though at the location of the AQS concentrations tend to increase when trees are added to the simulation.

\subsection{Exposure}

In fig. 4 the evolution of the mean $\mathrm{CO}$ exposure at each time-step (every 10 seconds) is presented for the seven considered pathways. In each graph, the exposure resulting from the effect of vegetation over the air quality is shown.

As it can be seen from the analysis of fig. 4, the values of the individual exposure to $\mathrm{CO}$ vary significantly, from pathway to pathway, ranging from values close to zero to $225 \mu \mathrm{g} . \mathrm{m}^{-3}$.h. From this fact it can be concluded that even in a small domain, a significant error can occur if a mean air quality value is used as a proxy for the exposure of the individuals that use that space. It can also be concluded that the presence of vegetation has no linear effect over the exposure values, since the results show that sometimes the scenarios where no vegetation is considered results in higher exposure, as well as the other way around. In scenarios A, B, C and D there are no significant differences between exposure with and without vegetation. In scenarios $\mathrm{E}$ and $\mathrm{F}$ exposure is higher in the scenarios that do not take into account the vegetation. This result is consistent with the conclusion drawn from the comparative analysis of the air quality fields (fig. 3). In scenario $G$, the exposure calculated considering trees is higher, due to the formation of additional CO hot-spots along the pathway.

\section{Conclusions}

As shown by the CFD simulations, local air quality is strongly dependent from the synergies between the meteorological conditions, the tridimensional configuration of the street-canyon and the presence of vegetation. The effect of the urban canopy (as a mosaic of buildings and trees) over the dispersion of air pollutants was shown to be complex and highly spatially dependent. In what concerns to the individual exposure of pedestrians, it can be concluded that, again, it is spatially dependent, according to the results on air quality. The variability of the exposure results obtained in this study shows the magnitude of the error that can be committed when the use of a single value of air quality as a surrogate of air pollution exposure. This conclusion is valid for a small domain, such as the one studied in this case, and it can be easily concluded that the error may be significantly higher when larger domains are considered. The fact that 
A

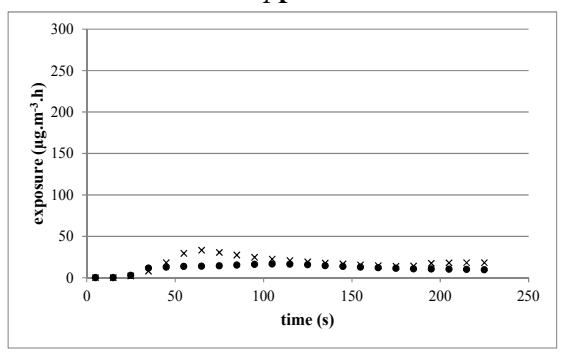

$\mathrm{C}$

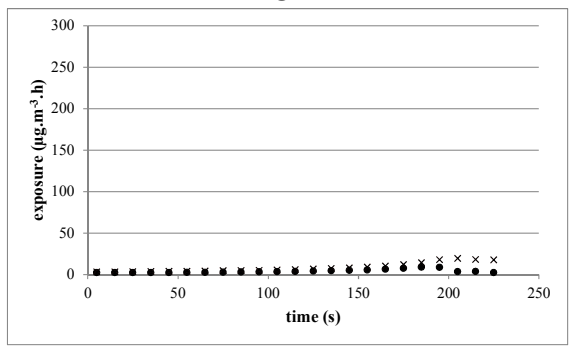

E

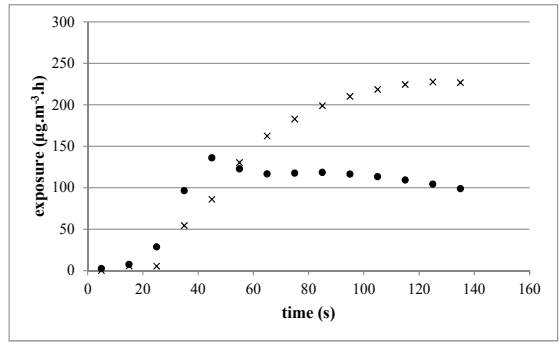

G

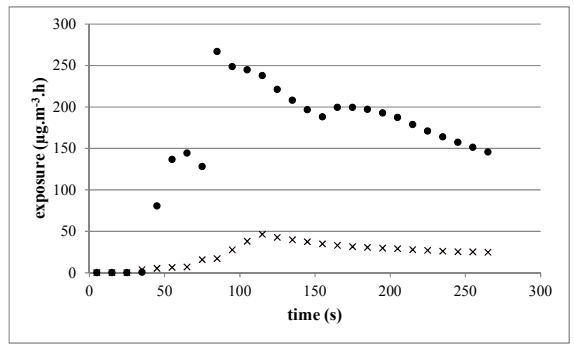

B

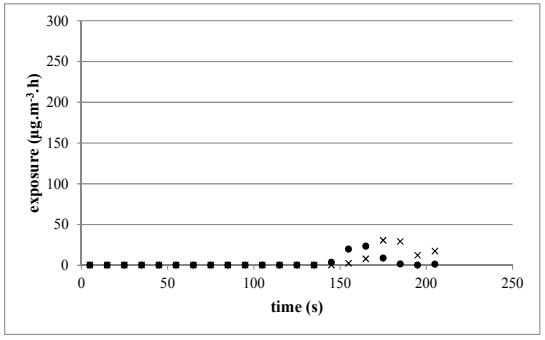

$\mathrm{D}$

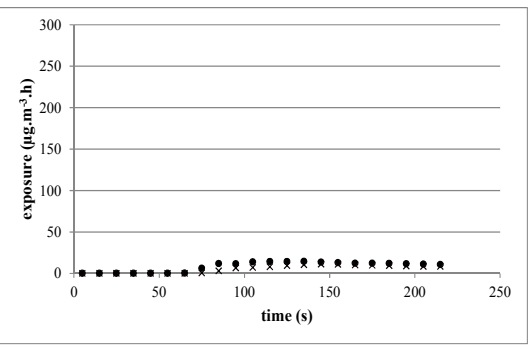

F

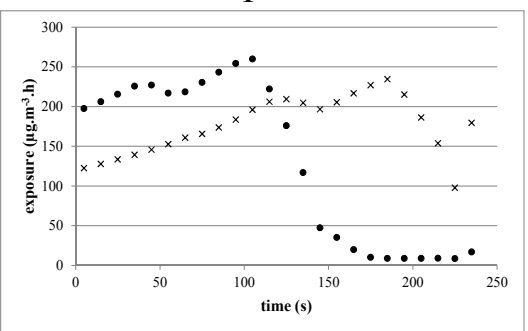

- vegetation $\times$ no vegetation

Figure 4: Time evolution of the $\mathrm{CO}$ exposure $\left(\mu \mathrm{g} \cdot \mathrm{m}^{-3} \cdot \mathrm{h}\right)$ for each of the seven considered pathways, considering and not the presence of vegetation in the dispersion simulation. 
the presence of vegetation may result in higher or lower exposures than a situation where no vegetation is considered, clearly indicates that, aiming at the improvement of public health, exposure studies are worth to develop when a planning intervention is studied. The simulation of different planning alternatives, where the position and type of vegetation are explored in terms of its effect in air quality and exposure, are assumed to be of vital importance for the pathway to greener and healthier cities. In addition, near future will probably bring knowledge-based routing techniques as a way to promote lower exposure of urban citizens to air pollutants in typical daily travels.

\section{Acknowledgements}

The authors would like to acknowledge the financial support of the $3^{\text {rd }}$ European Framework Program and the Portuguese Ministry of Science, Technology and Higher Education, through the Foundation for Science and Technology (FCT), for the Post-Doc grants of J.H. Amorim (SFRH/BPD/48121/2008) and J. Valente (SFRH/BPD/78933/2011) and for the funding of research project INSPIRAR (PTDC/AAC-AMB/103895/2008), supported in the scope of the Competitiveness Factors Thematic Operational Programme (COMPETE) of the Community Support Framework III and by the European Community Fund FEDER.

\section{References}

[1] EEA, Environment and Health, EEA report No. 10/2005. Office for Official Publications of the European Communities. 2005.

[2] Seaton, A., Macnee, W., Donaldson, K., \& Godden, D. 'Particulate air pollution and acute health effects', Lancet, 345, pp. 176-178. 1995.

[3] Samet, J.M., Dominic, F., Curriero, F.C., Coursac, I., \& Zeger, S.L. Fine particulate air pollution and mortality in 20 U.S. cities, 1987-1994. New England Journal of Medicine, 343, pp. 1742-1749, 2000.

[4] WHO, Development of WHO Guidelines for Indoor Air Quality. Report on a Working Group Meeting. World Health Organization Regional Office for Europe, 27 pp, 2007.

[5] Pope III, C.A. \& Dockery, D.W. Health effects of fine particulate air pollution: lines that connect, Journal of Air and Waste Management Association, 56, pp. 709-742, 2006.

[6] Finkelstein, M.M., Jerrett, M., Sears, M.R. Traffic air pollution and mortality rate advancement periods. American Journal of Epidemiology 160 (2), pp. 173-177, 2004.

[7] Hoek, G., Brunekreef, B., Goldbohm, S., Fischer, P. \& van den Brandt, P.A. Association between mortality and indicators of traffic-related air pollution in the Netherlands: a cohort study. Lancet, 360 (9341), pp. 12031209, 2002. 
[8] Hoffmann, B., Moebus, S., Mohlenkamp, S., Stang, A., Lehmann, N., Dragano, N., Schmermund, A., Memmesheimer, M., Mann, K., Erbel, R. \& Jockel, K.H. Residential exposure to traffic is associated with coronary atherosclerosis. Circulation, 116 (5), pp. 489-496, 2007.

[9] Tonne, C., Melly, S., Mittleman, M., Coull, B., Goldberg, R. \& Schwartz, J., 2007. A case-control analysis of exposure to traffic and acute myocardial infarction. Environmental Health Perspectives, 115 (1), pp. 5357, 2007.

[10] Amorim J.H., Rodrigues V., Tavares R. \& Borrego C. CFD Modelling of Tree-induced Effects on Flow and Dispersion of Traffic Emissions in City Centres. Advances in Urban Rehabilitation and Sustainability. ed. Panagopoulos T., Noronha T. and Beltrão J, WSEAS Press: Faro, pp. 171176, 2010.

[11] Sini, J.-F., Anquetint, S. \& Mestayer, P.G., Pollutant dispersion and thermal effects in urban street canyons, Atmospheric Environment, 30 (15), pp. 2659-2677, 1996.

[12] Hang, J., Sandberg, M., Li, Y. \& Claesson, L., Pollutant dispersion in idealized city models with different urban morphologies, Atmospheric Environment, .43, pp. 6011-6025, 2009.

[13] Kikuchi, A.; Nataya, N.; Mochida, A.; Yoshino, H.; Tabata, Y.; Watanabe, H. \& Jyunimura, Y., Field study of the influences of roadside trees and moving automobiles on turbulent diffusion of air pollutants and thermal environment in urban street canyons. Proc of 6th International Conference on Indoor Air Quality, Ventilation \& Energy Conservation in Buildings, Sendai, Japan, 2007.

[14] Gromke, C. \& Ruck, B., On the impacts of trees on dispersion processes of traffic emissions in street canyons. Boundary-Layer Meteorology, 131, pp. 19-34, 2009.

[15] Mochida, A., Tabata, Y., Iwata, T., Yoshino, H., Examining tree canopy models for CFD prediction of wind environment at pedestrian level. Journal of Wind Engineering and Industrial Aerodynamics, 96 (10-11), pp. 1667-1677, 2008.

[16] Buccolieri R., Gromke C., Di Sabatino S. \& Ruck B., Aerodynamic effects of trees on pollutant concentration in street canyons. Science of The Total Environment, 407 (19), pp. 5247-5256, 2009.

[17] Borrego, C., Tchepel, O., Costa, A.M., Amorim, J.H. \& Miranda, A.I., Emission and dispersion modelling of Lisbon air quality at local scale. Atmospheric Environment, 37, pp. 5197-5205, 2003.

[18] Wilson, J.D., A second order closure model for flow through vegetation. Boundary Layer Meteorology, 42, pp. 371-392, 1988.

[19] Green, S., Modelling turbulent air flow in a stand of widely spaced trees. J. Comp. Fluid Dyn. Appl., 5, pp.294-312, 1992.

[20] Li, Z., Lin, J.D. \& Miller, D.R., Air flow over and through a forest edge: a steady-state numerical simulation. Boundary Layer Meteorology, 51, pp. 179-197, 1990. 
[21] Raupach, M.R. \& Shaw, R.H., Averaging procedures for flow within vegetation canopies. Boundary-Layer Meteorology, 22, pp. 79-90, 1982.

[22] Kaimal, J.C. \& Finnigan, J.J., Atmospheric boundary layer flows: their structure and measurement, Oxford University Press: New York, 289 pp., 1994.

[23] Poggi, D., Porporato, A., Ridolfi, L., Albertson, J.D., Katul, G.G., The effect of vegetation density on canopy sublayer turbulence. BoundaryLayer Meteorology, 111, pp. 565-587, 2004.

[24] Ott W.R. Concepts of human exposure to air pollution. Environment International. 7, pp. 179-196, 1982.

[25] Miranda A.I., Amorim J.H., Martins V., Cascão P., Valente J., Ottmar R., Ribeiro L.M., Viegas D.X. \& Borrego C., 2011. Modelling the exposure of firefighters to smoke based on measured data. Proc. of $3^{\text {rd }}$ International Conference on Modelling, Monitoring and Management of Forest Fires Forest Fires, 2011.

[26] Hertel O., Leeuw F.D., Raaschou-Nielsen O., Jensen S.S., Gee D., Herbarth O., Pryor S., Palmgren F. \& Olsen E. Human exposure to outdoor air pollution - IUPAC Technical Report. Pure and Applied Chemistry, 73 (6), 933-958, 2001.

[27] Nowak, D.J., Crane, D.E. \& Stevens, J.C. Air pollution removal by urban trees and shrubs in the United States. Urban Forestry \& Urban Greening, 4(3/4), pp. 115-123, 2006.

[28] Chang, J.C. \& Hanna, S.R., Technical descriptions and user's guide for the BOOT statistical model evaluation software package, version 2.0., 62 pp, 2005. 